\title{
STUDY OF VARIATIONS IN THE DRAINING PATTERN OF INFERIOR MESENTERIC VEIN WITH ITS SURGICAL IMPORTANCE
}

\section{Neelesh Kanasker ${ }^{1}$, Preeti Sonje ${ }^{* 2}$, P. Vatsalaswamy ${ }^{3}$.}

${ }^{1}$ Assistant professor, Department of Anatomy, Dr. D. Y. Patil Medical College, Dr. D. Y. Patil Vidyapeeth Pimpri Pune, India.

${ }^{* 2}$ Associate professor, Department of Anatomy, Dr. D. Y. Patil Medical College, Dr. D. Y. Patil Vidyapeeth Pimpri Pune, India.

${ }^{3}$ Professor and Director Academics, Department of Anatomy, Dr. D. Y. Patil Medical College, Dr. D. Y. Patil Vidyapeeth Pimpri Pune, India.

\section{ABSTRACT}

Objectives: Variations in branching of vessels have always been an area of keen interest in the field of anatomy. Variations of arteries are known and mentioned in literature too although studies on pattern of drainage of veins are lacking. With this interest the following study was done with its importance in abdominal organ mobilization resections surgeries.

Materials and Methods: Present study was conducted with 24 formalin embalmed cadavers (20 Males and 4 Females) procured from department of anatomy, Dr. D. Y. Patil Medical College, Dr. D. Y. Patil Vidyapeeth Pimpri Pune, India.

Results: Inferior mesenteric vein drains venous blood from superior part of rectum, sigmoid colon and descending colon and generally terminate into splenic vein. However it may drain into superior mesenteric vein, at the junction of superior mesenteric and splenic vein or portal vein.

Conclusions: Knowledge of such variations of draining pattern of inferior mesenteric vein is an important prerequisite for surgeons to choose an adequate technique to avoid injury during colorectal surgeries especially at the time of inferior mesenteric vein ligation.

Key words: Inferior mesenteric vein, Draining pattern, Colorectal surgeries, Mobilization, Ligation.

Address for Correspondence: Dr. Preeti Sonje, Associate professor, Department of Anatomy, Dr. D. Y. Patil Medical College, Dr. D. Y. Patil Vidyapeeth Pimpri Pune, India. Mobile no: 08975781889 E-Mail: drpreetisalgar@gmail.com

Access this Article online

Quick Response code

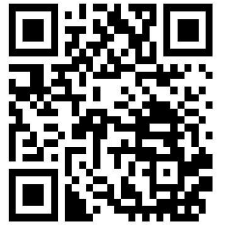

DOI: $10.16965 /$ ijar.2017.503

Journal Information

International Journal of Anatomy and Research

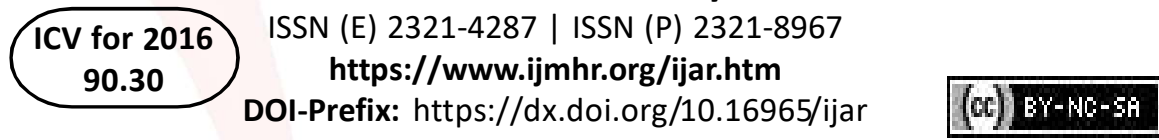

Article Information

Received: 11 Nov 2017

Peer Review: 13 Nov 2017

Revised: None
Accepted: 02 Jan 2018

Published (O): 05 Feb 2018

Published (P): 05 Feb 2018

\section{INTRODUCTION}

Inferior mesenteric vein (IMV) is one of the big venous channel draining venous blood from left part of gastrointestinal tract. It drains superior portion of rectum, sigmoid colon and descending colon. It begins as superior rectal vein from the rectal plexus through which it connects with middle and inferior rectal vein. The superior rectal vein leaves the pelvis and crosses left common iliac vessels medial to left ureter with the superior rectal artery, continuing up as inferior mesenteric vein [1]. It ascends vertically well to the left of the artery, beneath the peritoneal floor of the left infracolic compartment. It lies on left psoas major in front of gonadal vessels, ureter and genitofemoral nerve. At the 
upper limit of left infracolic compartment, just below the attachment of transverse mesocolon, it lies to the left of duodenojejunal flexure. Here it curves towards the right and often raises up ridge of peritoneum, this ridge may be excavated by a small recess of peritoneum which makes a shallow cave beneath, "the paraduodenal recess". IMV passes behind the lower border of the body of pancreas, in front of the left renal vein and joins the splenic vein.

Occasionally it curves to the right still more sharply passing behind the pancreas below and parallel with splenic vein, in front of superior mesenteric artery, opens directly into the superior mesenteric vein [2].

Knowledge of variations in the drainage pattern of IMV hold a great clinical importance in performing colorectal surgeries in relation to its ligation and collateral supply of splenic flexure.

\section{MATERIALS AND METHODS}

24 formalin embalmed cadavers (20 Males and 4 Females) were procured from department of anatomy and were dissected following steps given in Cunningham dissecting manual Volume 2 [3], meticulous dissection was carried out to note the draining pattern of IMV. Variations found were well noted and photographs were taken. Steps were as follows:

1. Mesentery of small intestine was exposed in the infracolic compartment by turning the transverse colon and its mesentery upwards.

2. Oblique attachment of mesentery of the small intestine was traced on the posterior abdominal wall.

3. Small intestine and its mesentery was reflected towards right side.

4. Peritoneum and fat from posterior abdominal wall between the mesentery and descending colon was removed.

5. Inferior mesenteric vessels were exposed which were medial to superior mesenteric vessels.

6. Inferior mesenteric vein was cleaned and traced till its opening in splenic vein.

\section{OBSERVATIONS AND RESULTS}

All the findings were recorded and assembled in tabulated form.
The different ways of termination of inferior mesenteric vein were noted as follows:

Type la - Inferior mesenteric vein terminating into splenic vein (normal)

Type Ib - Inferior mesenteric vein terminating into superior mesenteric vein

Type II-Inferior mesenteric vein terminating at the confluence of superior mesenteric and splenic vein.

Out of 24 cases ( 20 males and 4 females), 21 showed type I draining pattern while 3 showed type II draining pattern. Out of 21, 15 showed type la termination of IMV ( 13 males +2 females) and 6 showed type $\mathrm{lb}$ termination of IMV ( 5 males +1 female). Overall $87.5 \%$ showed type I and $12.4 \%$ showed type II draining pattern.

Table 1: Sex distribution of the cadavers according to termination of inferior mesenteric vein.

\begin{tabular}{|c|c|c|c|c|}
\hline Type & Male & Female & Total & Total \\
\hline Type la & 13 & 2 & 15 & \multirow{2}{*}{21} \\
\hline Type Ib & 5 & 1 & 6 & \\
\hline Type II & 2 & 1 & 3 & 3 \\
\hline Total & 20 & 4 & 24 & 24 \\
\hline
\end{tabular}

Table 2: Percentage of Type I and II for male and female cadavers.

\begin{tabular}{|c|c|c|c|c|c|c|}
\hline Type & Male & $\%$ & Female & $\%$ & Total & $\%$ \\
\hline I & 18 & $75 \%$ & 3 & $12.50 \%$ & 21 & $87.50 \%$ \\
\hline II & 2 & $8.30 \%$ & 1 & $4.10 \%$ & 3 & $12.40 \%$ \\
\hline
\end{tabular}

Table 3: Percentage of Type la and Ib for male and female cadaver.

\begin{tabular}{|c|c|c|c|c|c|c|}
\hline Type I & Male & $\%$ & Female & $\%$ & Total & $\%$ \\
\hline la & 13 & $54.10 \%$ & 2 & $8.30 \%$ & 15 & $62.40 \%$ \\
\hline Ib & 5 & $20.80 \%$ & 1 & $4.10 \%$ & 6 & $24.90 \%$ \\
\hline
\end{tabular}

Fig. 1: Type la draining pattern.

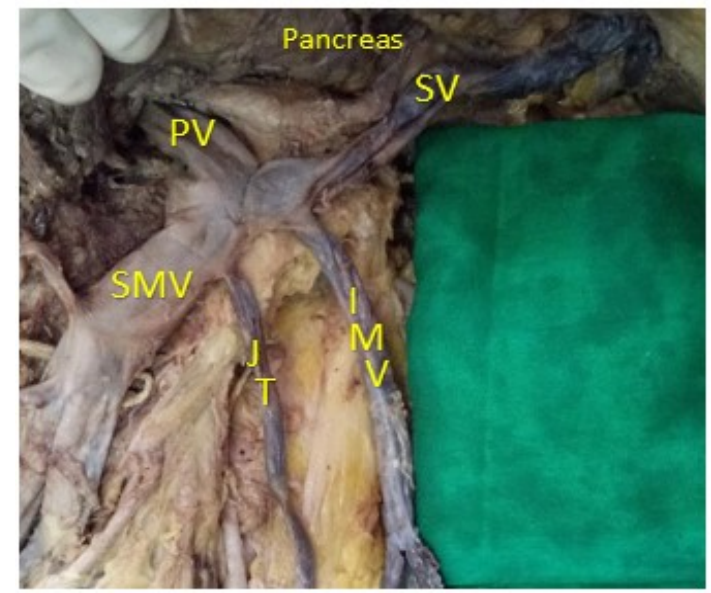

Type la: PV- Portal vein; SV-Splenic vein; IMV-Inferior mesenteric vein; JT-Jejunal tributary; SMV-Superior mesenteric vein. 
Fig. 2: Type Ib draining pattern.

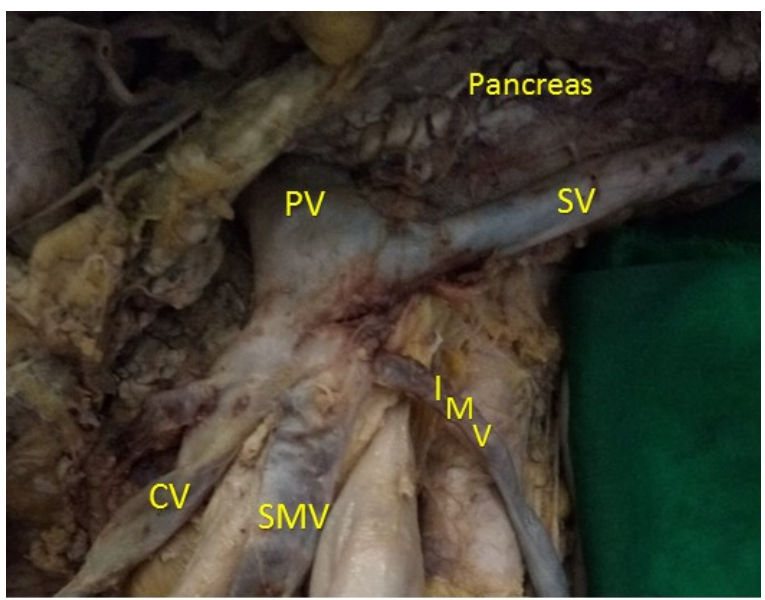

Type Ib: PV-Portal vein; SV-Splenic vein; IMV- Inferior mesenteric vein; SMV-Superior mesenteric vein; CVTColic Vein Tributary.

Fig. 3: Type II draining pattern.

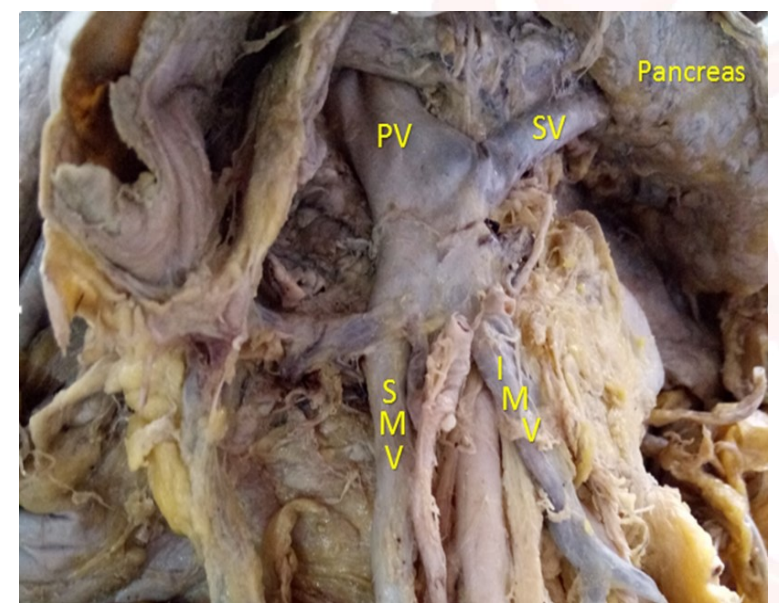

Type II: PV-Portal vein; SV- Splenic vein; IMV - Inferior mesenteric vein; SMV-Superior mesenteric vein.

\section{DISCUSSION}

Undrstanding the anatomy and applying appropiate technique accordingly are mandatory for improving the quality of surgery and paitent outcome.

Inferior mesentric vein ligation is indicated in certain circumstances during low anterior resction (LAR) surgeries of colon to gain more mobilization. Ligation of IMV without careful attention to the collateral vessels can affect the splenic flexure blood supply and might lead to variable degrees of left colonic congestion and ischemia.

There is no specifically distinct artery to splenic flexure of colon, and anatomic variations and collateral pathways are common [4]. Variabilty of splenic flexure blood supply has been described in different ways among the literature, but venous drainage from the left colon and splenic flexure usually is by severel tributaries that join the inferior mesentric vein (IMV). IMV is located close to ligament of Tretiz and passes below the lower border of the pancreas to join the splenic vein. Moreover IMV has variable ways of drainage. Usually, it drains into splenic vein but it may directly join the superior mesenteric vein (SMV) or at confluence between SMV and splenic vein [5].

In the usual situation, the inferior msesentreric artery (IMA) originates from left anterolateral aspect of the abdominal aorta around the L3-L4 level and supplies colon from the mid transverse portion to rectum. Initally the vessel has an inferior course of severl centimeters and then yeild to the left colic artery, which is the first branch of IMA and travels adjacent to the IMV. Usaullay it runs upwards and may reach splenic flexure where it birfurcates in $85 \%$ of cases. The asecnding branch of left colic artery makes anastomosis with the left branch of the middle colic artery in the splenic flexure region. The anastomotic channel formed close to the bowel is named as marginal artery of Drummond [6].

Genrally the marginal artery is sufficient for the left colic circulation after ligation of IMA, however patency of asending branch of the left colic artery might be primodial at the splenic flexure [7].

Apart from marginal artery of Drummond, Jean Riolan first described a tortous collateral vessel called as arc of Riolan or meandering marginal artery which is centrally located within the mesentery and forms a communication between the middle colic and left colic arteries in a region where there are uasually no major blood vessles. It is presnt in about $7-10 \%$ of population. Based on location, relation of marginal meandering aretry with inferior mesentric vein is technically more important during ligation procedues of vessels in colorectal resection surgeries. Accordingly follwing types of calssification was found:

Type A: Artery emerges from the right side of IMV, passes at the lower border of pancreas and crosses the inferior mesentric vein at that level.

Type B: Artery runs close to IMV until lower border of pancreas. 
Type C: No collateral artery related to IMV.

Among these type $A$ and $C$ are most common [8].

Recommendations during IMV ligation to gain more medial mobilization at the level of the lower border of pancreas are to carefully check the anatomy at that area. Therefore this area is called as "a critical zone of IMV". This zone is traingular in shape, formed by IMV, lower border of pancreas and the left colic artery. This zone is not always empty and might have meandering mesenteric artery at the lower border of pancraes (Type A) or collateral vessles running very close to it (Type B). Thus careful dissection and skeletonization of IMV root ' a critical zone of IMV' before ligation is mandatory to preserve collateral vessels for the watershed area and to avoid further injury [9].

\section{CONCLUSION}

Varaibilty of the collateral blood supply to the splenic flexure and its relation with IMV makes it a part of our concern during colorectal surgical procedures. Knowledge of their anatomy is prerequisite for surgeons to choose adequate techinque in order to prevent them from being damaged and to carry out successful resection of a segment otherwise ligation of meandering marginal artery at the root of IMV causes compromised blood supply to left colon resulting in congestion, ischemia and different levels of colitis or anastomotic dehisence.

\section{Conflicts of Interests: None REFERENCES}

[1]. Gray H.THE ANATOMICAL BASIS OF MEDICINE AND SURGERY 38th ed. Peter L. Williams, Elsevier Churchill Livingstone;1995; p.1603.

[2]. LAST'S ANATOMY REGINAL AND APPLIED. $9^{\text {th }}$ ed. R.M.H.McMINN,Churchill Livingstone;1994;p.328.

[3]. Romanes GJ. Cunningham's Manual Of Practical Anatomy. $15^{\text {th }}$ ed. Vol 2. New York: Oxford Medical Publications;1986; p.137-149

[4]. Walker TG. Mesenteric vasculature and collateral pathways. Semin Intervent Radiol. 2009;26:167-174

[5]. Netter Frank H. E ssentials Atlas of Human Anatomy. ISBN 0-914168-18-5 Copyright 1987.

[6]. Sakorrafas GH, Zouros E, Peros G. Applied vascular anatomy of colon and rectum: clinical implications for surgical oncologist. Srug Oncol. 2006;15:243255

[7]. Horton KM, Fishman EK. Volumme rendered 3D CT of the mesenteric vasculature: normal anatomy, anatomic varinats and pathlogical conditions. Radiodaignosis. 2002;22:161-172.

[8]. Michels NA, Siddharth P, Kornblith PL, Parke WW. The variant blood supply to the desending colon, rectosigmoid and rectum based on 400 diessection. Its imortance in regionl recestions: a review of medical litreature. Dis Colon Rectum. 1965;8:251-278.

[9]. Al- Asari SF, Lim D, Min BS, Kim NK. The Relation between Inferior Mesenteric Vein Ligation and Collateral Vessels to Splenic Flexure:Antomical Landmark, Techniquel Preccautions and Clinical Significance. Yenois Med J.2013;54(6):14841490.

How to cite this article

Neelesh Kanasker, Preeti Sonje, P. Vatsalaswamy. STUDY OF VARIATIONS IN THE DRAINING PATTERN OF INFERIOR MESENTERIC VEIN WITH ITS SURGICAL IMPORTANCE. Int J Anat Res 2018;6(1.2):4897-4900. DOI: 10.16965/ijar.2017.503 